\author{
M. A. Tashkandi ${ }^{1 *}$, J. A. Al-Jarrah ${ }^{1}$, M. Ibrahim ${ }^{2}$ \\ ${ }^{1}$ Mechanical Engineering Department, Faculty of Engineering, Northern Border University, \\ Saudi Arabia \\ ${ }^{2}$ Chemical and material Engineering Department, Faculty of Engineering, Northern Border \\ University, Saudi Arabia, on leave from Industrial Engineering Department, Faculty of \\ Engineering, Fayom University, Egypt
}

\title{
INCREASING OF THE MECHANICAL PROPERTIES OF FRICTION STIR WELDED JOINTS OF 6061 ALUMINUM ALLOY BY INTRODUCING ALUMINA PARTICLES
}

\begin{abstract}
The main aim of this investigation is to produce a welding joint of higher strength than that of base metals. Composite welded joints were produced by friction stir welding process. 6061 aluminum alloy was used as a base metal and alumina particles added to welding zone to form metal matrix composites. The volume fraction of alumina particles incorporated in this study were 2, 4, 6, 8 and $10 \mathrm{vol} \%$ were added on both sides of welding line. Also, the alumina particles were pre-mixed with magnesium particles prior being added to the welding zone. Magnesium particles were used to enhance the bonding between the alumina particles and the matrix of 6061 aluminum alloy. Friction stir welded joints containing alumina particles were successfully obtained and it was observed that the strength of these joints was better than that of base metal. Experimental results showed that incorporating volume fraction of alumina particles up to 6 vol\% into the welding zone led to higher strength of the composite welded joints as compared to plain welded joints
\end{abstract}

Keywords: Friction stir welding, aluminum alloys, metal matrix composite

\section{INTRODUCTION}

Friction stir welding (FSW) is a solid-state joining and surface modification technique were invented at the Welding Institute of UK in 1991, some it variations included of Friction stir processing (FSP) [1]. Friction stir welding (FSW) has been recently used in many significant applications and considered as very important joining processes [2]. Researchers attempt to produce an efficient joints (comparing the ratio of the strength of the welded joints to the strength of the base metal) by widely investigating the welding process parameters [3]. The main welding process parameters that can be controlled are the rotational speed, the transverse speed, the axial force applied by the shoulder of the tool on the work-piece, the tool tilt angle and tool geometry [4-7]. Heat input during the welding process is affected by 
the processing parameters of FSW [8]. Also, the process parameters contribute to welding defects, microstructure and residual stresses [9]. In general, many researchers demonstrated that the properties of the welded joints are less than that of the base metal under different combinations of processing parameters. Also, mechanical properties increased with increasing heat generated during FSW process up to a certain limit [10, 11]. Welded joints with high heat input fractured mostly at the advance side on the heat affected zone adjacent to the thermo-mechanically affected zone, while the low heat input joints fractured at the weld zone [9, 12]. Beside welding parameters; many investigations were carried out to enhance the welded joints quality. Some researchers improved the mechanical properties of the welded joints by carrying Pre/Post heat treatment [13-15]. Others found that the use of $\mathrm{CO}_{2}$ liquid cooling after the welding process resulted in higher joint quality [16]. Other researchers studies found out the weld quality can be improved by enhancing the plastic flow near the tool by applying additional preheating or presoftening mechanisms on the workpiece. Auxiliary energy was used to assist FSW process to heat/soft the workpiece[17]. The assisting energy used was classified in to two categories, thermal and mechanical energies. Many types of thermal energies were used to preheat the workpiece like, electricity, induction, laser, plasma, hot gas stream, gas torch, etc. [18-21]. Assistance energy helped to go farther in friction stir welding method to joined hard and dissimilar metals. Ultrasonic vibrations only the mechanical mechanism used to soften the workpiece without changing in process temperature [22].

Friction stir processing (FSP) has been used to enhance the surface properties of the Aluminum alloy sheets [23]. As a novel surface modifying technique, friction stir processing (FSP), was developed for fabrication of surface composite [24]. FSP used to fabricate surface composites and modify microstructure features of aluminum alloys [25]. Surface composite sheets of AA2024/ $/ \mathrm{Al}_{2} \mathrm{O}_{3}$ have been fabricated by friction stir processing. It has been found that the average tensile strength of friction processed samples was improved by $10 \%$, while the elongation decreased by $50 \%$ due to presence of alumina particle in the matrix. The hardness of 6063 aluminum plates were increased by adding alumina particles to the plate surface during FSP [26]. The rotation speed and the transverse welding speed affected the reinforcement particle distribution in the modified surface sheet of aluminum reinforced by $\mathrm{SiC}$ particles as reported by Kurt et al [27].

The current investigation is focused into studying the effects of introducing alumina particles to the welding zone of 6061 aluminum alloy butt joints produced by friction stir welding. The authors are proposing that this process will produce a composite welded joints that are expected to possess higher mechanical properties than the conventionally friction stir welded joints of 6061 aluminum alloy.

\section{EXPERIMENTAL}

Rectangular Plates of 6061 aluminum alloy of $6 \mathrm{~mm}$ thicknesses were used in this investigation. The chemical composition of 6061 aluminum alloys and mechanical properties are given Tables 1 and 2 respectively. The aluminum alloy sheets were cut into 250x150 mm by a manual cutting machine.

Table 1. Chemical composition of the 6061Al alloy

\begin{tabular}{|c|c|c|c|c|c|c|c|c|c|}
\hline Element & $\mathrm{Si}$ & $\mathrm{Mg}$ & $\mathrm{Cu}$ & $\mathrm{Fe}$ & $\mathrm{Mn}$ & $\mathrm{Ti}$ & $\mathrm{Zn}$ & $\mathrm{Cr}$ & $\mathrm{Al}$ \\
\hline Wt.\% & 0.75 & 0.9 & 0.5 & 0.5 & 0.15 & 0.05 & 0.03 & 0.03 & Rest \\
\hline
\end{tabular}


Table 2. Mechanical properties of the 6061Al alloy

\begin{tabular}{|c|c|c|c|}
\hline $\begin{array}{c}\text { Yield strength, } \\
\text { MPa }\end{array}$ & $\begin{array}{c}\text { Ultimate Tensile } \\
\text { Strength, MPa }\end{array}$ & Elongation, \% & Hardness, HV \\
\hline 110 & 208 & 14 & 65 \\
\hline
\end{tabular}

Alumina particles of $25 \mu \mathrm{m}$ were mixed with magnesium particles and added to the welding zone before the welding was carried out. The volume fraction of alumina particles was taken as 2, 4, 6, 8 and $10 \%$. The volume fraction of the alumina particles is calculated relatively to the volume of the aluminum alloy under the shoulder of the welding tool. The weight percentage of the magnesium particles were also calculated based on welding zone. The total weight percentage of magnesium was taken to be $4 \mathrm{wt} \%$ in the aluminum alloy as previously recommended [28]. After that $3.1 \mathrm{wt} \%$ of magnesium was added (6061 aluminum alloy already has $0.9 \mathrm{Mg}$ ). The mixture of magnesium and alumina particles were then placed in blind holes of $2 \mathrm{~mm}$ diameter and $5.7 \mathrm{~mm}$ depth that were drilled on both sides of the welding line as shown in Fig.1. A $6 \mathrm{~mm}$ pin with a square profile and a flat shoulder diameter of $21 \mathrm{~mm}$ was used to weld and mix the alumina particles along with the base metal in the welding area during the welding process. The welding tool was made from high carbon steel. A special fixture was used to hold the plates to be welded on the table of a vertical milling machine to achieve a friction stir welding process. The welding rotational speed was varied as 760, 1120, and $1300 \mathrm{rpm}$ while the welding transverse speed was set to 1 and 1.5 $\mathrm{mm} / \mathrm{sec}$. A spring-loaded cell was used to maintain the applied axial force at $6.8 \mathrm{kN}$.

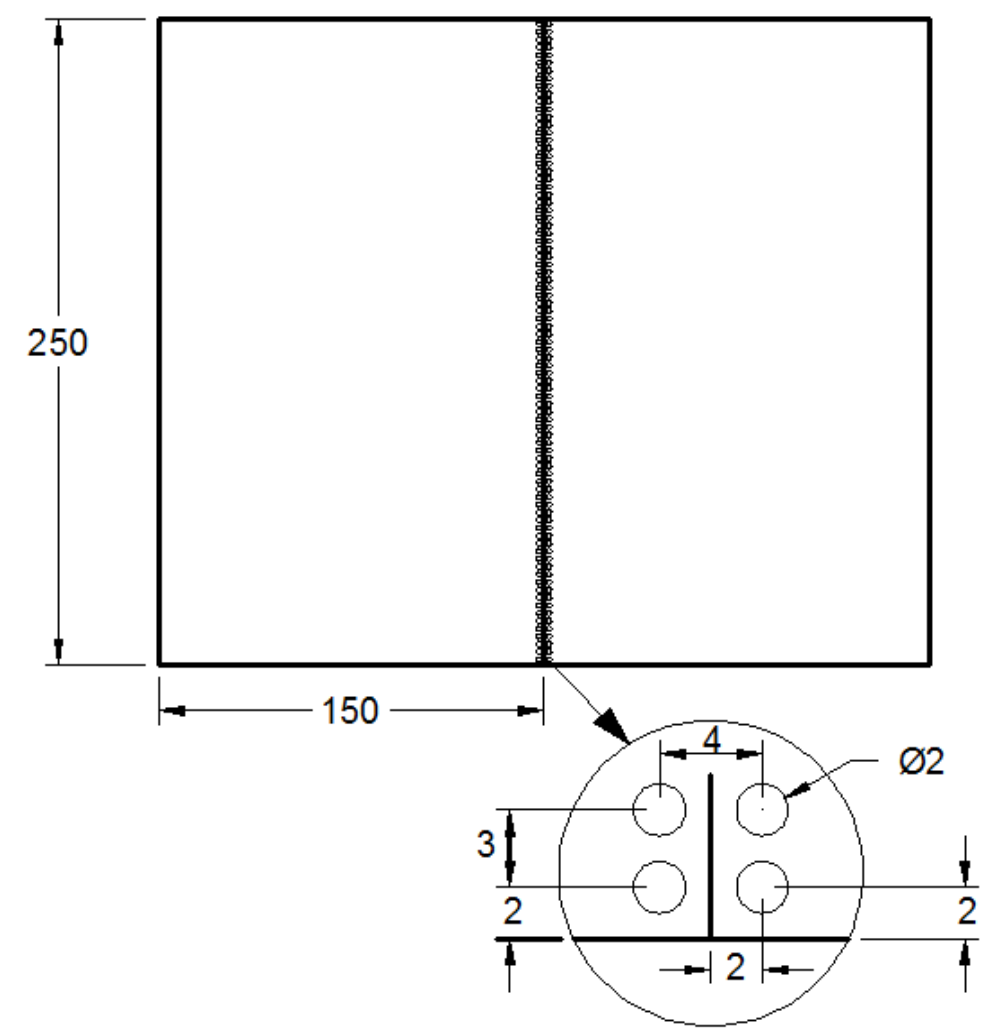

Fig. 1. Dimensions of square butt joints with the blind holes 
Tensile specimens were cut using EDU-VR1-Mill 2 CNC machine, in the transverse direction of the welding orientation and prepared according to ASTM:E8. The specimens had a gauge diameter of $12 \mathrm{~mm}$ and gauge length of $90 \mathrm{~mm}$ as shown in Fig.2. The tensile tests were carried out on a WDW-20 computer controlled electromechanical universal testing machine. The average value of three measurements was recorded and reported for each combination of welding parameters being considered. Vickers microhardness was measured with $4.9 \mathrm{~N}$ load and a dwell period of $10 \mathrm{~s}$ using a digital display of HVS-1000 microhardness. The average value of five measurements was recorded for each combination of welding parameters being considered. The microstructure of the material was examined within samples cut from welding zone via MEIJI MT 8530 optical microscope. The specimens were prepared according to standard metallographic methods, and etched for 2030 seconds with Keller's reagent, $2 \% \mathrm{HF}, 3 \% \mathrm{HCl}, 5 \% \mathrm{HNO}_{3}$ and the rest was distilled water to reveal the grain boundaries.

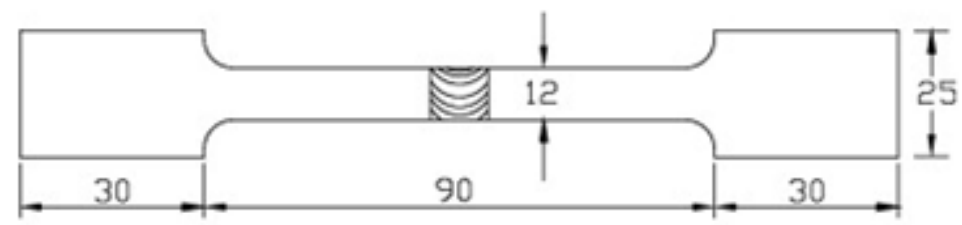

Fig. 2. Tensile specimen

\section{RESULTS AND DISCUSSION}

Tensile properties such as the ultimate tensile strength and the elongation of friction stir welded joints of 6061 aluminum alloy with alumina particles were evaluated. Three specimens were tested and the average of the results was recorded. Proper incorporation of the alumina particles inside the welding area indicates that the failure should occur in the base metal. Therefore, tensile samples were cut along the welding line in order to measure the tensile strength of the welded zone. The incorporation of alumina particles inside the aluminum matrix depends on the homogenous distribution of the alumina particles and the well bonding between the alumina particles and the aluminum matrix [28]. Addition of $4 \mathrm{wt} \%$ magnesium to pure aluminum enhances the bonding between the alumina particles and the aluminum matrix [29].

The variation of the welding properties with the added alumina particles on the ultimate tensile strength of the welding zone was measured in all cases for the welding parameters. The volume fraction of added alumina was changed from 0 to 10 percent as mentioned earlier. Fig. 3 shows the variation of ultimate tensile strength with the transverse welding speed. The transverse welding speed was set as 1.0 and $1.5 \mathrm{~mm} / \mathrm{sec}$ for each volume fraction while the rotational speed was kept constant at $1120 \mathrm{rpm}$. Fig. 3 shows that composite welded zones of 4 vol\% alumina particles possess the highest ultimate tensile strength. Also these composite joints have ultimate tensile strength more than that of base metal. Moreover, the produced composite welded joints that contain of 2 and 6 vol\% of alumina particle have ultimate tensile strength more than that of plain welded joints (plain welded joint produced using FSW from base metal without alumina additions). However, for volume fractions of alumina particles more than $6 \mathrm{vol} \%$, the ultimate tensile strength of composite welded joints declined and 
became less than that of plain welded joints produced at the same welding parameters. The addition of the alumina particles seems to increase the ultimate tensile strength of the welded joints to a maximum value at a volume fraction of $4 \%$. Anymore addition of alumina particles leads to an opposite result which decreases the strength of the welded joints as indicated in Fig. 3.

The heat induced during the welding process affects the quality of the welded joints [8]. In general and for a constant rotational speed, as the welding transverse speed increases, less heat is generated and induced to the welding zone which deteriorates the quality of the welded joint [10]. However, in the case of composite materials, the generated heat during friction stir welding process can enhance the incorporation and mixing of the alumina particles. Thus, the bonding strength between the alumina particles and the aluminum matrix is increased. The distribution of the reinforcement particle affects the strength of the welded joints. It was reported that as the transverse speed increases more uniform distribution of $\mathrm{SiC}$ in commercial pure aluminum particle is produced during friction stir processing [27]. Fig. 3 shows that in general the ultimate tensile strength of the composite welded joints prepared at welding speed of $1.5 \mathrm{~mm} / \mathrm{sec}$ is better than that prepared at $1 \mathrm{~mm} / \mathrm{sec}$. But at a volume fraction of 4 vol\% alumina particles, the ultimate tensile strength of the composite welded joints fabricated at welding speed of $1 \mathrm{~mm} / \mathrm{s}$ was higher than that of the composite welded joints produced at welding speed of $1.5 \mathrm{~mm} / \mathrm{sec}$. This result would be due to more heat introduced during the welding process. Then the generated heat is more suitable to incorporate the alumina particles and create good bonding. However, at higher volume fractions of alumina particles, the composite welded joints produced at welding speed of 1.5 $\mathrm{mm} / \mathrm{sec}$ have ultimate tensile strength higher which is than that of composite welded joints produced at welding speed of $1.0 \mathrm{~mm} / \mathrm{sec}$. At both conditions of welding speed, the process failed to incorporate alumina particles of volume fractions more than that of $6 \mathrm{vol} \%$.

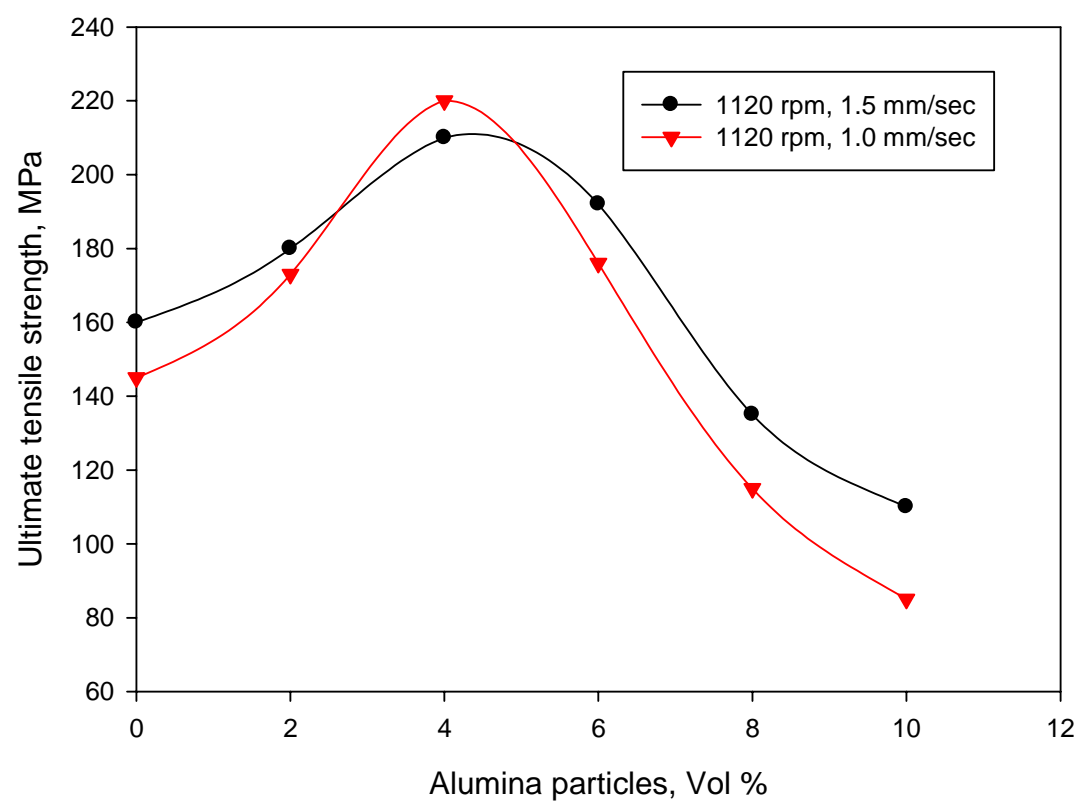

Fig. 3. Effect of welding speed on ultimate tensile strength of the welded area

The effect of the rotational speed on the ultimate tensile strength of the welding zone at different volume fraction of alumina particles is shown in Fig. 4. The Welding speed was kept constant at $1.5 \mathrm{~mm} / \mathrm{sec}$ and three rotational speed values (760, 1120, and $1300 \mathrm{rpm}$ ) were 
considered in these experiments. Fig. 4 indicates that composite welded joints produced at a rotational speed of $1300 \mathrm{rpm}$ with alumina particles more than 4 vol\% had higher ultimate tensile strength compared by ones prepared at other rotational speeds. On the other hand, composite joints produced with less alumina volume fractions had the highest ultimate tensile strength at rotational speed of $1120 \mathrm{rpm}$. At high rotational speeds (1300 rpm), more heat is generated during the welding process, which enhances the incorporation and mixing of the alumina particles inside the aluminum matrix in the welding zone. The presence of the alumina particles in welding zone reduces the viscosity of aluminum-alumina substrate, which needs more heat to stir and mix. This may explains why more alumina particles can be incorporated inside the matrix at higher rotational speeds. Also, more uniform distribution of the reinforcement particles inside the aluminum matrix is produced [27].

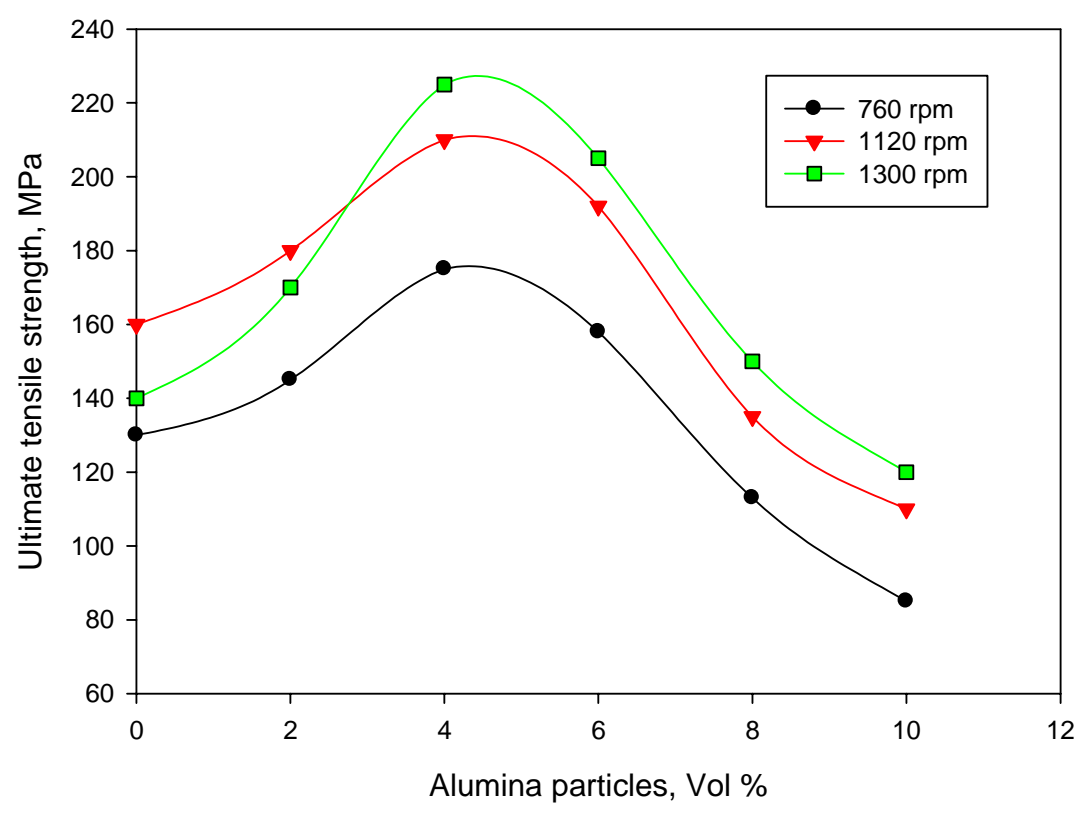

Fig. 4. Effect of rotational speed on ultimate tensile strength of welded area

Fig. 5 presents the ultimate tensile strength of composite welded zone at different volume fraction of alumina particles. It depicted that composite welded joints of $4 \mathrm{vol} \%$ alumina particles produced at rotational speed of $1300 \mathrm{rpm}$ have superior ultimate tensile strength of $225 \mathrm{MPa}$, which is more than that of the received base metal (208 MPa). Also, composite welded joints of $6 \mathrm{vol} \%$ alumina particles produced at the higher rotational speed of $1300 \mathrm{rpm}$ have an ultimate tensile strength of $205 \mathrm{MPa}$ which is approximately equal the strength of the base metal. Fig. 6 shows a typical curve of the effect of alumina volume fraction on the percentage elongation of the welding zone. It is clearly shown that at higher volume fraction of alumina particles, the composite welded joints failed as a brittle material. This may be due to a cluster of alumina particles which leads to fracture at lower tensile loads. Moreover, poor inadequate mixing of the alumina particles with the aluminum matrix in the welded zone can lead to weak joints. 


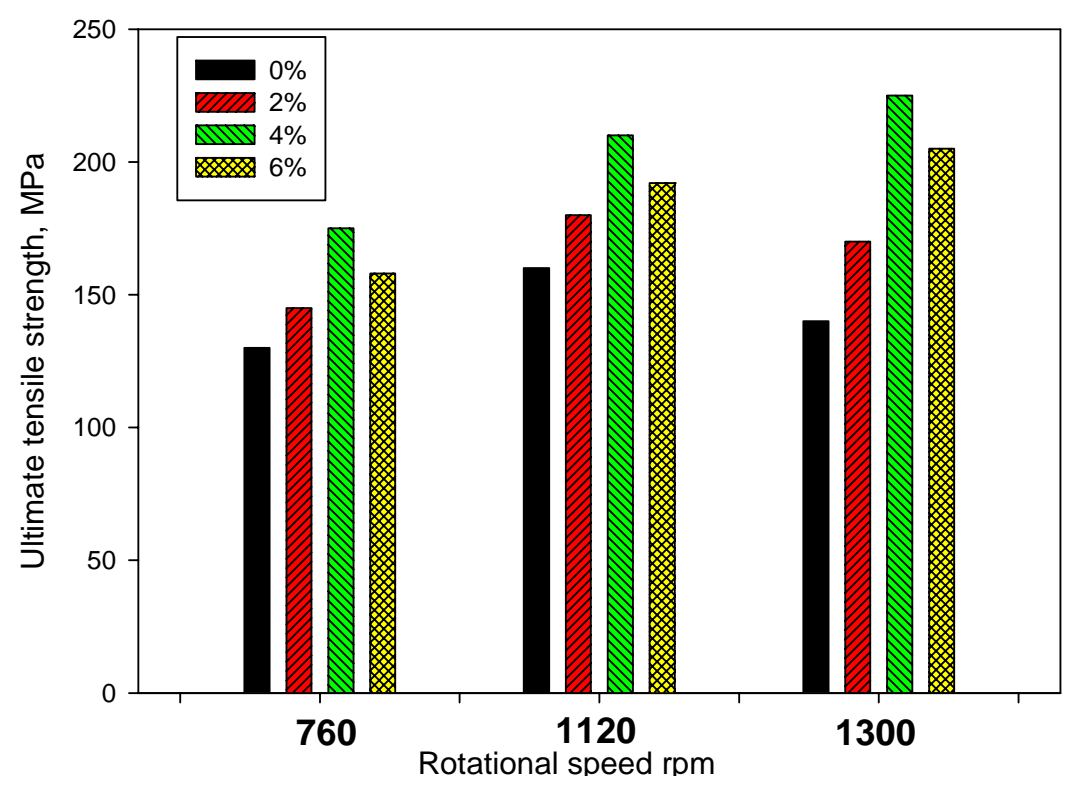

Fig. 5. The effect of alumina particles volume fractions on ultimate tensile strength

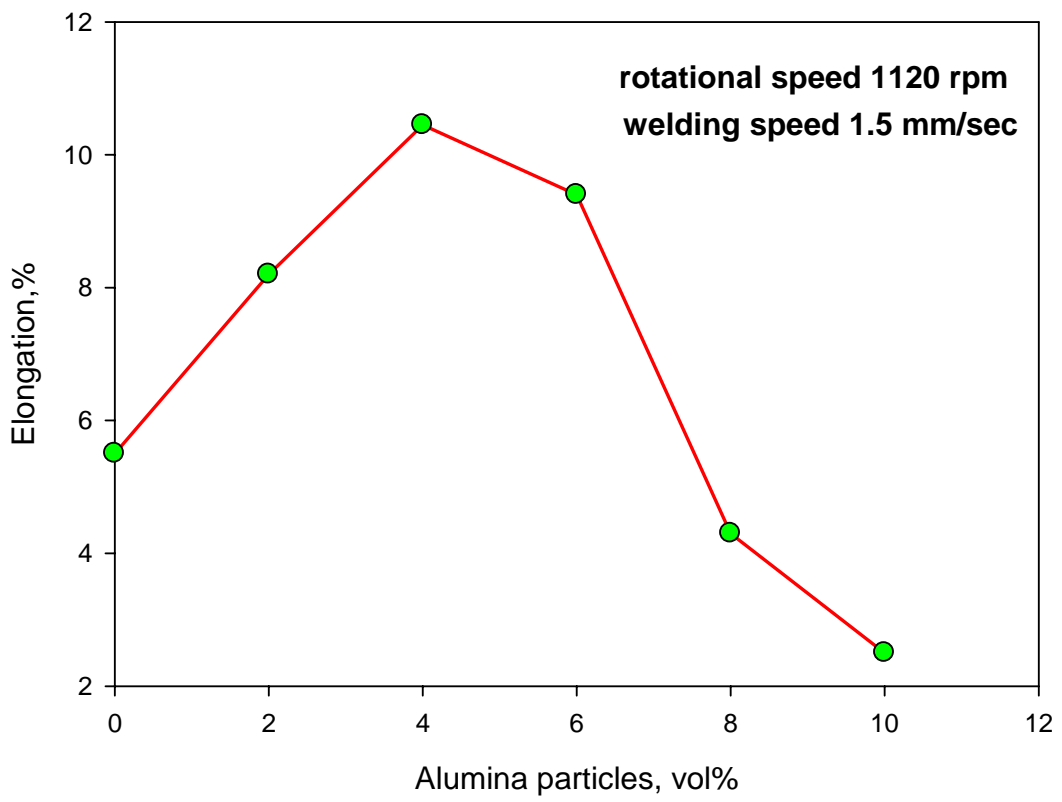

Fig. 6. The effect of alumina particles on elongation

The hardness across the welding zone for some samples was measured using Vickers microhardness testing machine. Five readings of hardness values were taken from the weld face and the average was recorded. Then, these average values were plotted against the distance from the welding center. Fig. 7 shows a typical curve of Vickers microhardness. The hardness of the composite welded zone is higher than that of the base metal due to the presence of hard particles (alumina particles). In addition, as the volume fraction of alumina particles increased, the microhardness of the composite welded zone increased. Fig. 8 shows 
the microhardness of the composite welded joints at different volume fraction of alumina particles. The average of five reading were recorded and plotted. These experiments were carried out at a rotational speed of $1120 \mathrm{rpm}$ and welding speed of $1.5 \mathrm{~mm} / \mathrm{sec}$. It is clearly shown that the microhardness increased as the volume fraction of alumina particles increased up to 6 vol\%, followed by a drop of hardness at higher volume fractions of alumina particles. This would have occurred due to clustered of alumina particles.

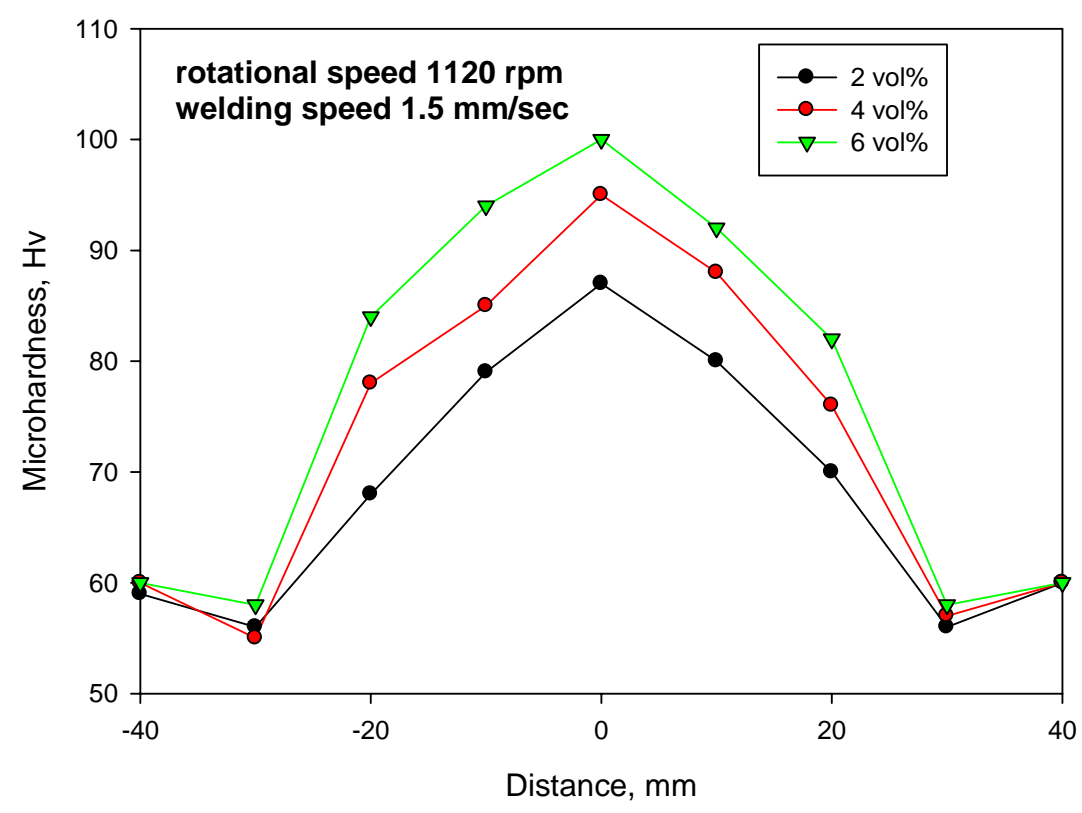

Fig. 7. Microhardness vs distance at different vol\% of alumina particles

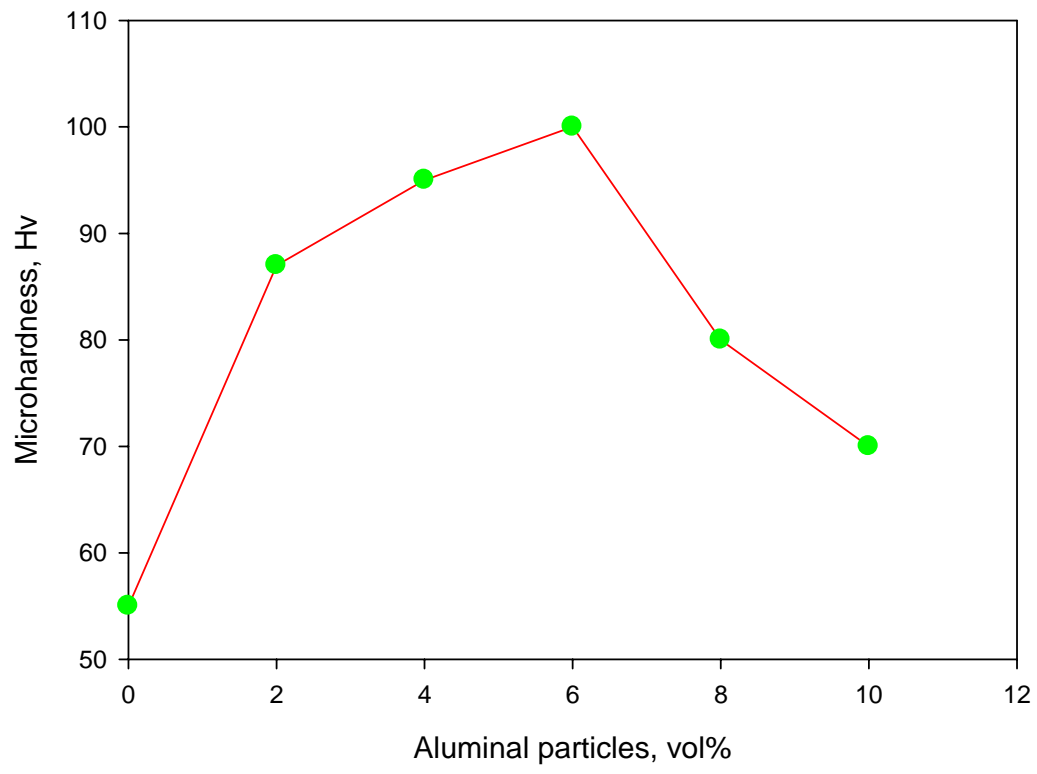

Fig. 8. Effect of alumina volume fraction on microhardness 
Fig. 9 shows the microstructures of the composite welded joints at different volume fractions of alumina particles. These joints were produces at a rotational speed of $1300 \mathrm{rpm}$ and welding speed of $1.5 \mathrm{~mm} / \mathrm{sec}$. Fig. 9(a) shows a microstructure of a joint with 2 vol\% alumina particles; it indicates that the grains are coarse and elongated with homogenous distribution of alumina particles. Increasing the volume fraction of alumina particles to 4 vol\%, leads the grains to become more equiaxed. In addition some dendrites appear, along with homogenous distribution of alumina particles as shown in Fig. 9(b). Higher volume fractions of alumina particles (6 vol\%) led to fine grains as shown in Fig. 9(c). Moreever increasing the volume fraction of alumina particles to $8 \mathrm{vol} \%$ led to make the grains even finer, and also produces of clusters of alumina particles as shown in Fig. 9(d).

The efficiency of the welded joints depends on the welding quality of the joints. As indicated earlier, efficiency is defined as the ratio of the strength of the welded joints to the strength of the base metal [30]. The efficiency of joints that are defect free can reach up to $90 \%$ [31]. By adding alumina particles to aluminum alloys to fabricate metal matrix composites, the strength of the welded joints can be further enhanced [32]. As a result, the strength of the composite welded joints which were successfully obtained in this investigation agreed with previous results regarding the welding of metal matrix composites by friction stir welding process [33].
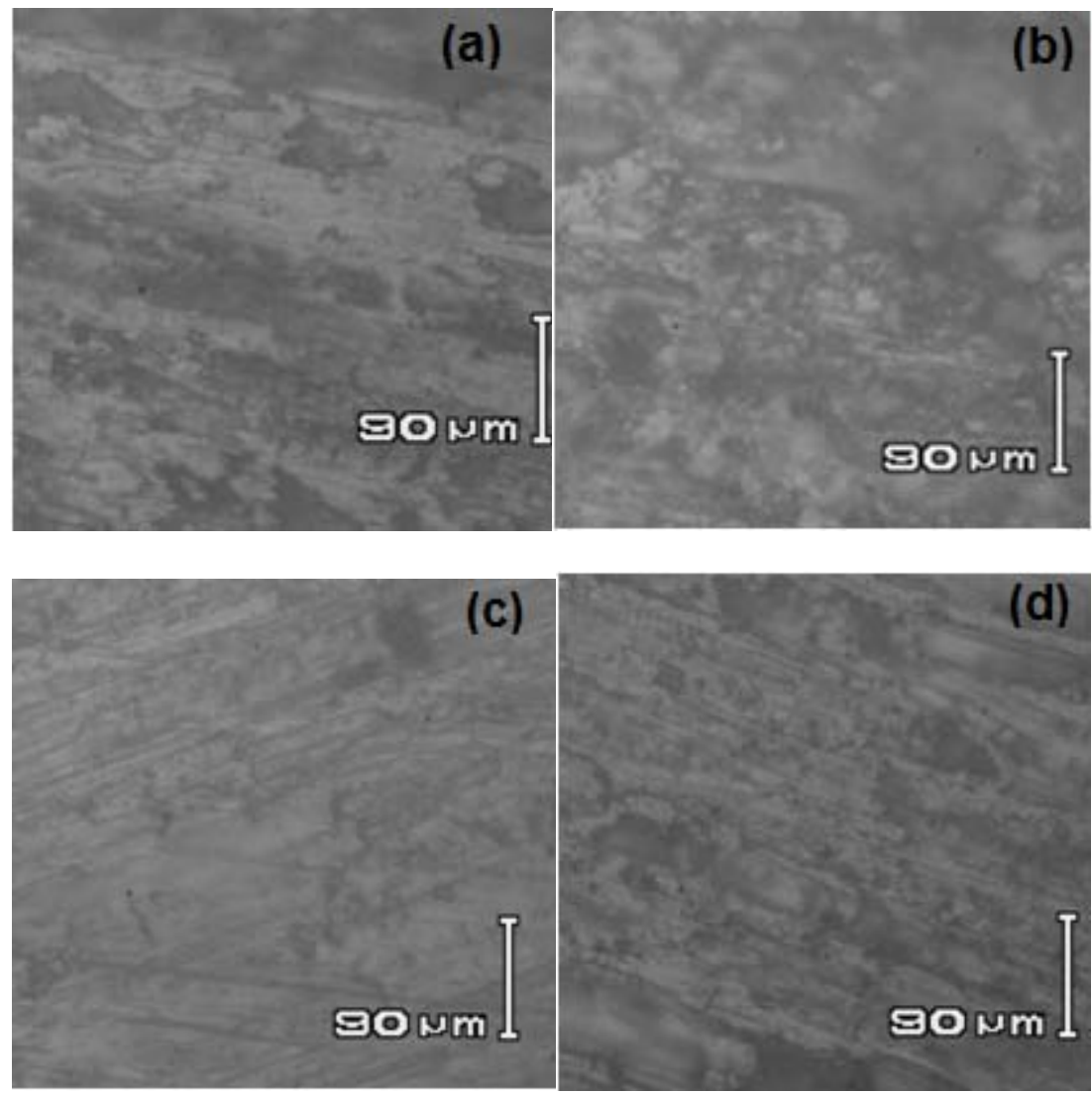

Fig. 9. Microstructure of the welded joints produced at rotational speed of $1300 \mathrm{rpm}$ and have (a) $2 \%$, (b) $4 \%$, (c) $6 \%$ and (d) $8 \%$ volume fraction of alumina particles 


\section{CONCLUSIONS}

In this study, 6061 aluminum alloy sheets of thickness $6 \mathrm{~mm}$ were welded by friction stir welding process and alumina particles were added to welding zone to enhance the quality of the welded joints. The authors were able to successfully produce composite welded joints. In addition, it was indicated that a suitable combination of rotational speed and welding speed may incorporate more volume fraction of alumina particles. The correct joints with superior strength have 4 vol\% of alumina particles, were produced at rotational speed of $1300 \mathrm{rpm}$, and welding speed of $1.0 \mathrm{~mm} / \mathrm{sec}$. Furthermore, the hardness of the welded joints were increased as the volume fraction of alumina particles increased up to 6 vol\%. Moreover as volume fraction of alumina particles is increased, the hardness of the welded joints decreased. Finally, incorporation of alumina particles into 6061 aluminum alloy increased the strength of the welded joints during FSW process, but leads to decrease in the elongation of the joints.

\section{ACKNOWLEDGMENT}

The authors wish to acknowledge the approval and support of this research study by Grant 413-1436-5 from Deanship of Scientific Research in Northern Border University, Arar, KSA.

\section{REFERENCES}

1. Thomas, W.M., Nicholas, E.D., Needham, J.C., Murch, M.G., Templesmith, P., and Dawes, C.J.,: Improvement relating to friction welding, WO/1993/010935, International Patent application Number PCT/GB92/02203 TWI, (1993).

2. Lee, W. B., Yeon, Y.M., Jung, S. B.: Mechanical properties related to microstructural variation of $6061 \mathrm{Al}$ alloy joints by friction stir welding. Material Transactions 45 (2004) 1700-1705.

3. FU, R.D., Sun, R.-C., Zhang, F.-C., Liu, H.-J.: Improvement of formation quality for friction stir welded joints. Welding Journal (2012) 169-173.

4. Hirata T., Oguri T., Hagino H., Tanaka T., Chung S. W., Takigawa Y., Higashi K.: Influence of friction stir welding parameters on grain size and formability in 5083 aluminum alloy, Materials Science and Engineering 456 (2007) 344-349.

5. Dongxiao Li, Xinqi Yang, Lei Cui, Fangzhou He, Hao Shen: Effect of welding parameters on microstructure and mechanical properties of AA6061-T6 butt welded joints by stationary shoulder friction stir welding. Materials and Design 64 (2014) 251-260.

6. Chaitanya Sharma, Dheerendra Kumar Dwivedi , Pradeep Kumar.: Effect of welding parameters on microstructure and mechanical properties of friction stir welded joints of AA7039 aluminum alloy. Materials and Design 36 (2012) 379-390.

7. Rohit K., Ratnesh K., Singh R., Bajpai, A.K.: Mechanical properties of friction stir welded 6061 aluminum alloy. Interanational J. of Engg. Research (IJERT) 2 (2013) 74-80.

8. Pasquale Cavaliere.: Friction stir welding of Al alloys: analysis of processing parameters affecting mechanical behavior. Procedia CIRP 11 (2013) 139-144.

9. Elatharasana G., Senthil V.S.: An experimental analysis and optimization of process parameter on friction stir welding of AA 6061-T6 aluminum alloy using RSM. Procedia Engineering 64 (2013) 1227-1234. 
10. Al-Jarrah J.A., Sawalha S., Abumansour T.A., Ibrahim M., Al-Rashdan M., Al-Qahsi D.A.: Welding quality and mechanical properties of aluminum joints prepared by friction stir welding, Material and design 56 (2014) 929-936.

11. Rajakumar S., Muralidharan C., Balasubramanian, V.: Influence of friction stir welding process and tool parameters on strength properties of AA7075-T6 aluminium alloy joints. Materials and Design 32 (2011) 535-545.

12. Murshid Imam, Vikranth Racherla, Kajal Biswas.: Effect of post-weld natural aging on mechanical and microstructural properties of friction stir welded 6063-T4 aluminium alloy. Materials and Design 64 (2014) 675-686.

13. Sivaraj P., Kanagarajan D., Balasubramanian V.: Effect of post weld heat treatment on tensile properties and microstructure characteristics of friction stir welded armour grade AA7075-T651 aluminium alloy. Defence Technology 10 (2014) 1-8.

14. Boonchouytana W., Ratanawilaib T., Muangjunbureec P.: Effect of Pre/Post Heat Treatment on the Friction Stir Welded SSM 356 Aluminum Alloys. Procedia Engineering 32 (2012) 11391146.

15. Chaitanya Sharma N, Dwivedi D.K., Pradeep Kumar.: Influence of pre-weld temper conditions of base metal on microstructure and mechanical properties of friction stir weld joints of Al-ZnMg alloy AA7039. Materials Science \& Engineering A620 (2015) 107-119.

16. Nan $\mathrm{Xu}$, Rintaro Ueji, Yoshiaki Morisada, Hidetoshi Fujii.: Modification of mechanical properties of friction stir welded $\mathrm{Cu}$ joint by additional liquid $\mathrm{CO}_{2}$ cooling. Materials and Design 56 (2014) 20-25.

17. Padhy G.K, Wu C.S., Gao S.: Auxiliary energy assisted friction stir welding status review", Sci. and Tech. of welding joining, 20 (2015) 631-649.

18. Liu X., Lan S., Ni J.: Electrically assisted friction stir welding for joining Al 6061 to TRIP780 steel. J. Mater. Process. Technol. 219 (2015) 112-123.

19. Alvarez I., Cid V., Pena G., Sotelo J., Verdera D.: Assisted friction stir welding of carbon steel: use of induction and laser as preheating techniques', 1st edn, Vol. 7, in 'Friction stir welding and processing VII', (ed. Mishra R. et al.., (2013) 117-126; Warrendale, PA, TMS (The Minerals, Metals \& Materials Society), John Wiley and Sons.

20. Song K.H., Tsumura T., Nakata K.: Development of microstructure and mechanical properties in laser-FSW hybrid welded Inconel 600. Mater. Trans. 50 (2009) 1832-1837.

21. Joo S. M.: Joining of dissimilar AZ31B magnesium alloy and SS400 mild steel by hybrid gas tungsten arc friction stir welding', Met. Mater. Int., 19 (2013) 1251-1257.

22. Shi L., Wu C.S., Liu X.C.: Modeling the effects of ultrasonic vibration on friction stir welding. Journal of Materials Processing Technology 222 (2015) 91-102.

23. Wais M. H., Salman J. M., Al-Roubaiy, A. O.: Effect Of friction stir processing on mechanical properties and microstructure of the cast pure aluminum. International J. of Scientific \& Technology Research 2 (2013) 154-163.

24. Mishra R.S., Ma Z.Y., Charit I.: Friction stir processing: A novel technique for fabrication of surface composite. Material Science and Engineering A341(2003) 307-310.

25. Essam F., Samah S.M., Sayed A., El-Sayed El-Kady: Efeect of friction stir processing parameters on the tensile strength of surface composite aluminum alloy. Int. J. of Adv. Res.(IJAR) 5 (2017) 2061-2065.

26. Britto Joseph G., Saikiran J. J., Mageshwaran G.: Improving surface hardness of aluminum plates by adding alumina powder by friction stir process. Int. J. of Chem. Tech. Res. 9 (2016) 587-593. 
27. Kumit. A., Ilyas U., Eren C.: Surface modification of aluminum by friction stir processing. J. of material processing Tech. (2011) 313-317.

28. Ghosh P.K., Doctoral thesis, Mixing characteristics and mechanical properties of casting Al(Mg) - $\mathrm{Al}_{2} \mathrm{O}_{3}$ composits, University of Roorkee, Roorkee, India (1986).

29. champion J.A., Keene B.J., Silwood J.M.: Wetting of aluminum oxide by molten aluminum and other metals, J. of Mater. and Sci. 4 (1969) 39-49.

30. Ashwani K., Shakti S.G., Alok K.: Heat input and joint efficiency of three welding process TIG, MIG and FSW using AA6061. Int. J. of mech. Engg. and Rob. Res. 1 (2014) 89-94.

31. Thube R.S, Pal S.K.: Influence of tool pin profile and welding parameters on friction stir weld formation and joint efficiency of AA 5083 joint produced by friction stir welding. Int. J. of Innovative of advance engineering (2014) 1:1-8.

32. Kamat S.V., Hirth J.P., Mehrabian R.: Mechanical properties of particulate reinforced Aluminum matrix composites, Acta Metall. 7 (1989) 2395-2402

33. Salih O. S., Hengan Ou, Sun W., McCartney D.G.: A review of friction stir welding of aluminum matrix composites. Material and design (2015) 61-71. 